\title{
Effect of Weld Properties on the Crush Strength of the PWR Spacer Grid
}

\author{
Kee-nam Song ${ }^{1}$ and Sang-hoon Lee ${ }^{2}$ \\ ${ }^{1}$ VHTR Technology Development Group, Korea Atomic Energy Research Institute, Daejeon 305353, Republic of Korea \\ ${ }^{2}$ Nuclear Fuel Cycle Waste Treatment Research Division, Korea Atomic Energy Research Institute, Daejeon 305353, Republic of Korea
}

Correspondence should be addressed to Kee-nam Song, knsong@kaeri.re.kr

Received 29 March 2012; Accepted 19 June 2012

Academic Editor: Yan Yang

Copyright ( $\odot 2012$ K.-n. Song and S.-h. Lee. This is an open access article distributed under the Creative Commons Attribution License, which permits unrestricted use, distribution, and reproduction in any medium, provided the original work is properly cited.

\begin{abstract}
Mechanical properties in a weld zone are different from those in the base material because of different microstructures. A spacer grid in PWR fuel is a structural component with an interconnected and welded array of slotted grid straps. Previous research on the strength analyses of the spacer grid was performed using base material properties owing to a lack of mechanical properties in the weld zone. In this study, based on the mechanical properties in the weld zone of the spacer grid recently obtained by an instrumented indentation technique, the strength analyses considering the mechanical properties in the weld zone were performed, and the analysis results were compared with the previous research.
\end{abstract}

\section{Introduction}

A PWR fuel assembly consists of spacer grids, fuel rods, a top nozzle, a bottom nozzle, guide tubes, and an instrumentation tube as shown in Figure 1. Among them, the spacer grid is a structural component which is an interconnected array of slotted grid straps and is welded at intersections to form an egg-crate structure. From a structural point of view, the spacer grid is required to have enough crush strength under lateral loads so that nuclear fuel rods are maintained in a coolable geometry, allowing control rods to be inserted [1]. The capacity of a spacer grid to resist lateral loads is usually characterized in terms of its crush strength, and it was reported [2] that the lateral crush strength of the spacer grid is closely related with the welding quality of the spacer grid.

Welding is a very convenient and widely used method to join simple metallic parts with a complicated structure by the use of adhesive and cohesive attractive forces between metals [3]. Microstructures in the weld zone, including a weld (or fusion zone) and a heat affected zone (HAZ), are different from that in a base material, as shown in Figure 2 [3]. Consequently, the mechanical properties in the weld zone are different from those in the base material to some extent. When a welded structure is loaded, the mechanical behavior of the welded structure might be different from the case of a structure with homogeneous mechanical properties. Nonetheless, mechanical properties in the welded structure have been neglected in many structural analyses [4-7] of spacer grids due to a lack of mechanical properties in the weld zone. Usually, the general way to obtain the mechanical properties in the weld zone is by taking tensile test specimens in the fusion zone and HAZ, and by performing a standard tensile test. However, when the weld zone is very narrow and the interfaces are not clear, it is hard to take tensile test specimens in the weld zone. The reason for this is that the mechanical properties in the base material are usually used in the structural analyses in the welded structure. It has been recently known that the ball indentation technique has the potential to be an excellent substitute for a standard tensile test, especially in the case of small specimens or propertygradient materials such as welds [8-10].

In this study, to investigate the effect on the mechanical behavior of the spacer grid when using weld mechanical properties, strength analyses considering the weld mechanical properties recently obtained [11] by an instrumented 


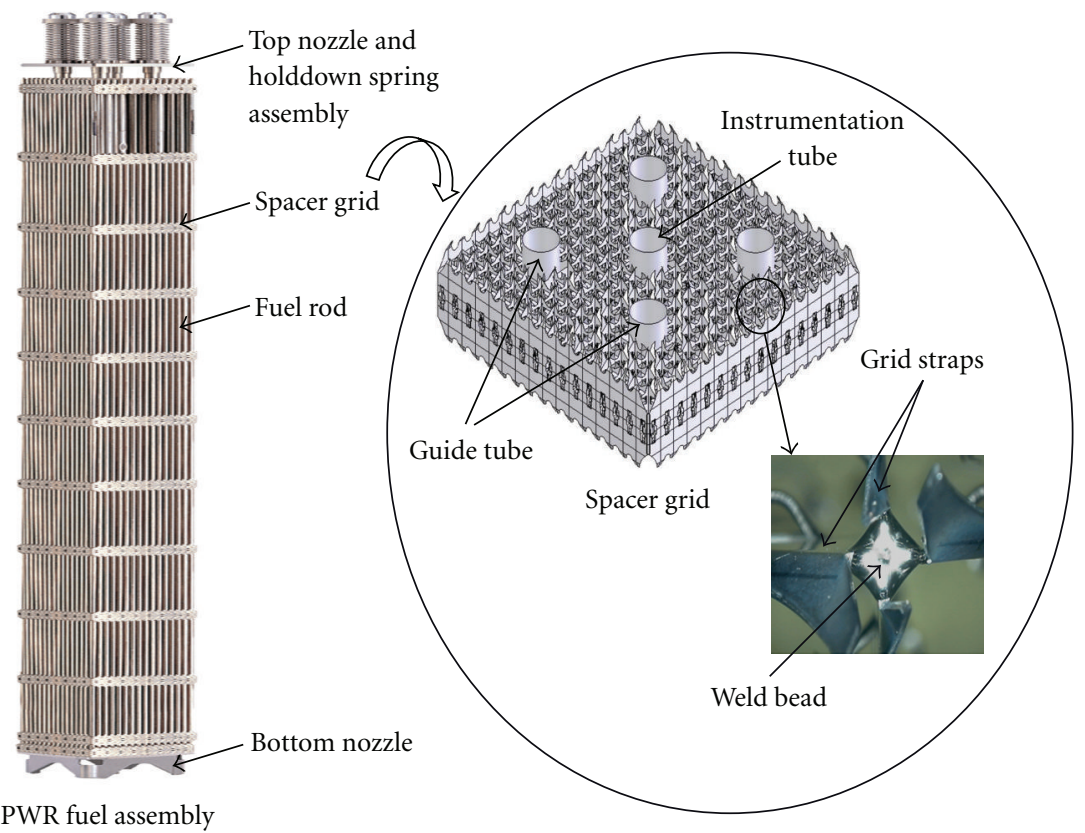

FIgURE 1: PWR fuel assembly and spacer grid.

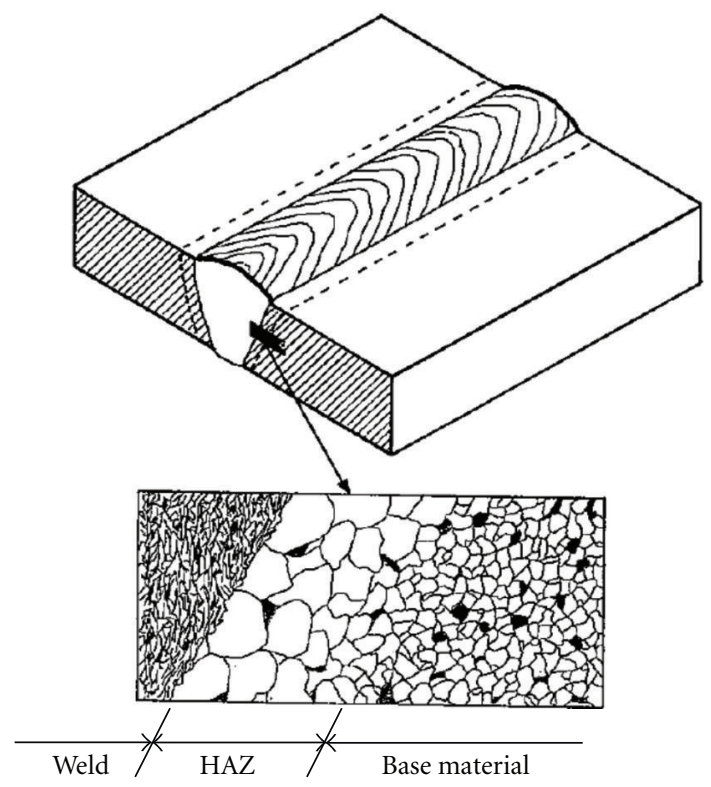

Figure 2: Microstructure near the weld [3].

indentation technique are performed, and the analysis results were compared with the results of the previous research using base material properties.

\section{Structure of a Zircaloy Spacer Grid in PWR Fuel}

Zircaloy is the prevailing material of a spacer grid because of its low neutron absorption characteristic and extensive successful in-reactor use. A Zircaloy spacer grid and a weld bead at the intersections of the straps are shown in Figure 1. Spot welding by a laser beam welding technique is prevalent in most of the Zircaloy spacer grid manufacturing vendors, for the purpose of a smaller bead size and a larger weld penetration at the welding parts. Generally, a spacer grid with a smaller bead size leads to a smaller pressure drop of the coolant flowing along the nuclear fuel assembly, which consequently leads to a reduction in the load on a reactor coolant pump. In addition, a spacer grid with a deeper weld 

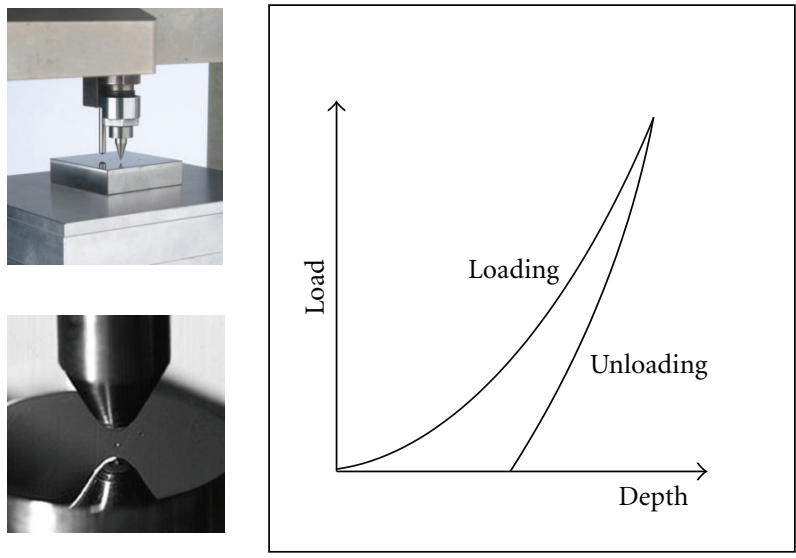

Indentation load-depth curve

FIGURE 3: Schematic representation of indentation load-depth curve.
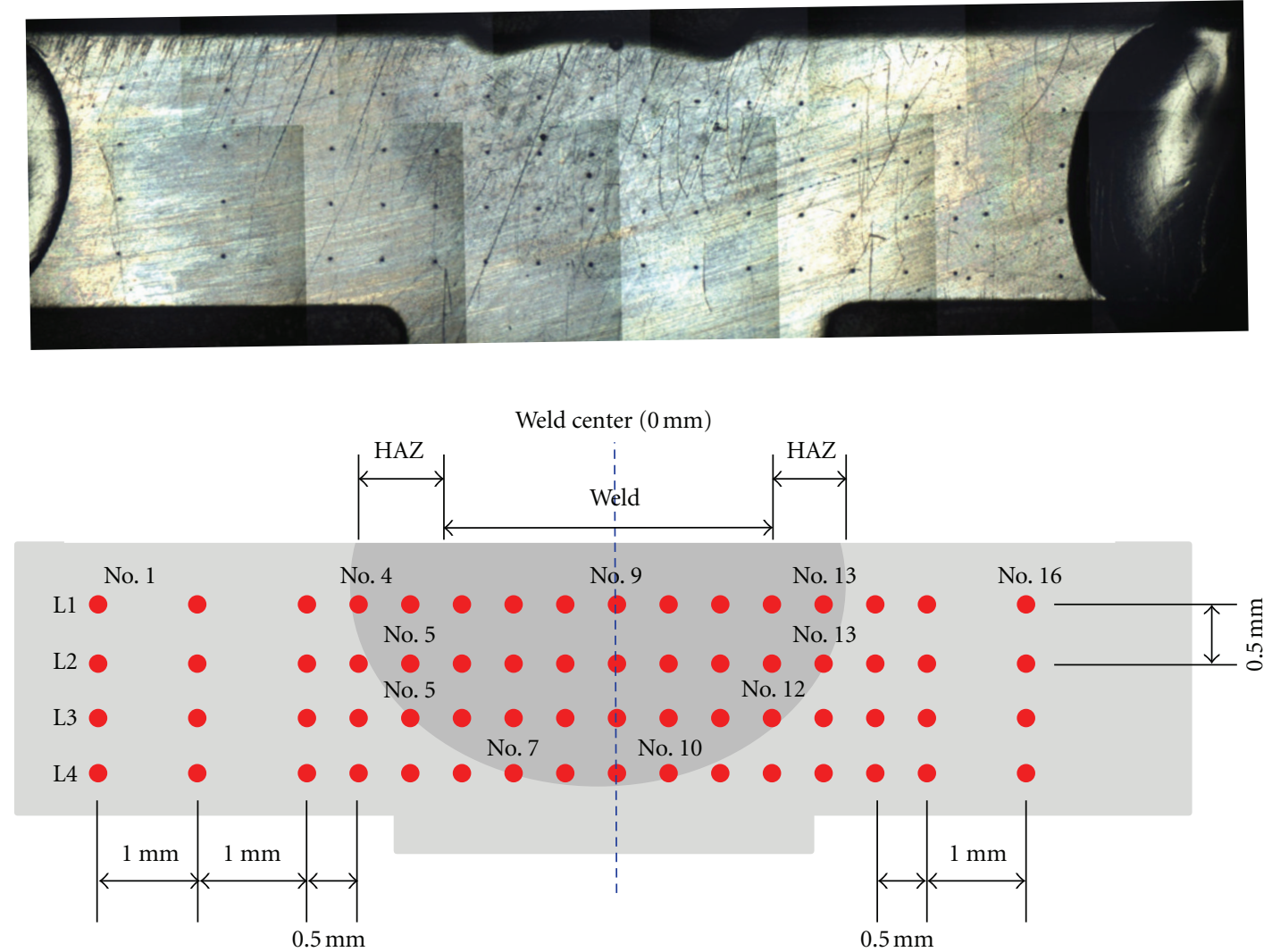

FIGURE 4: Etched specimen and indented positions in welded Zircaloy-4 strip.

penetration results in larger crush strength of the spacer grid [4]. The diameter of the weld bead is about $2 \mathrm{~mm}$ and the width of the HAZ is just below $1 \mathrm{~mm}$ for a Zircaloy spacer grid strip $0.457 \mathrm{~mm}$ thick. That is to say, the weld zone including the weld bead (or fusion zone) and HAZ is very narrow, and the interfaces are not so clear. Thus, it is usually difficult to obtain the mechanical properties in the weld zone from the conventional tensile test specimen.

\section{Mechanical Properties in Weld Zone}

3.1. Instrumented Indentation Method. Indentation is known to be a remarkably flexible mechanical test to obtain properties including hardness, Young's modulus, yield stress, and tensile strength with minimal specimen preparation $[8,9]$. The additional advantage of indentation is the ability to obtain the mechanical properties in a narrow or inaccessible 

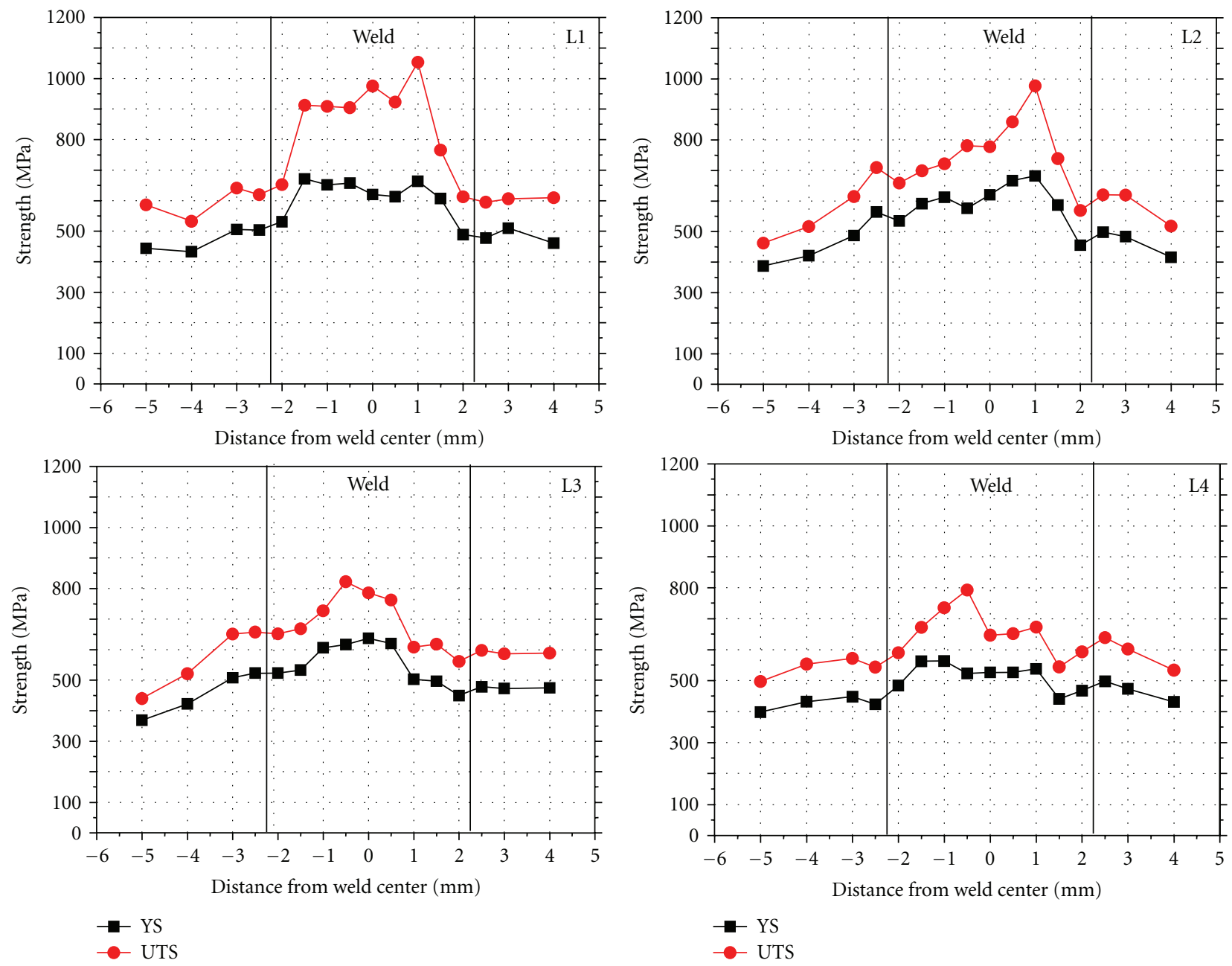

FIGURE 5: Variation of mechanical properties in welded Zircaloy-4 strip.

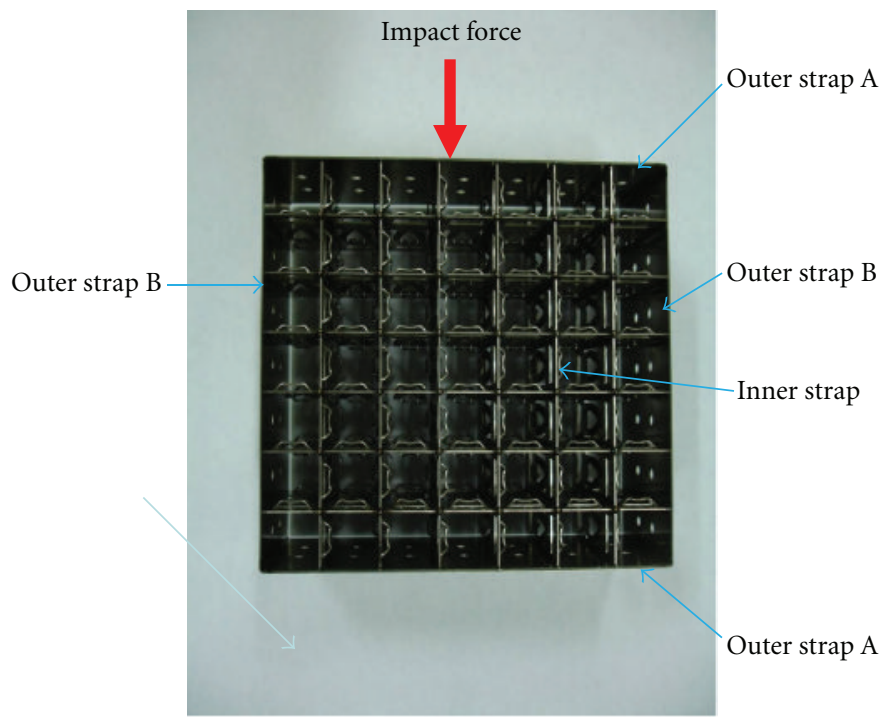

FIgURE 6: Subsize $(7 \times 7$ array) spacer grid specimen. 


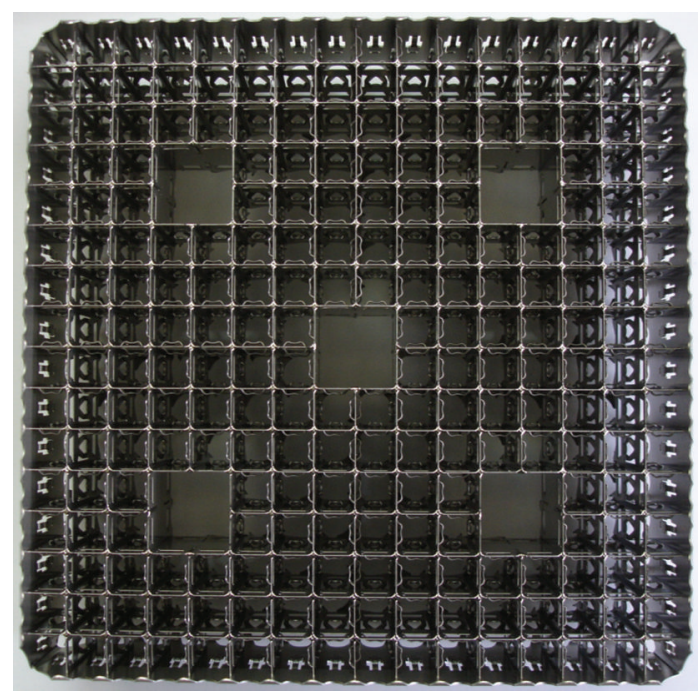

Figure 7: Full-size $(16 \times 16$ array) spacer grid specimen.

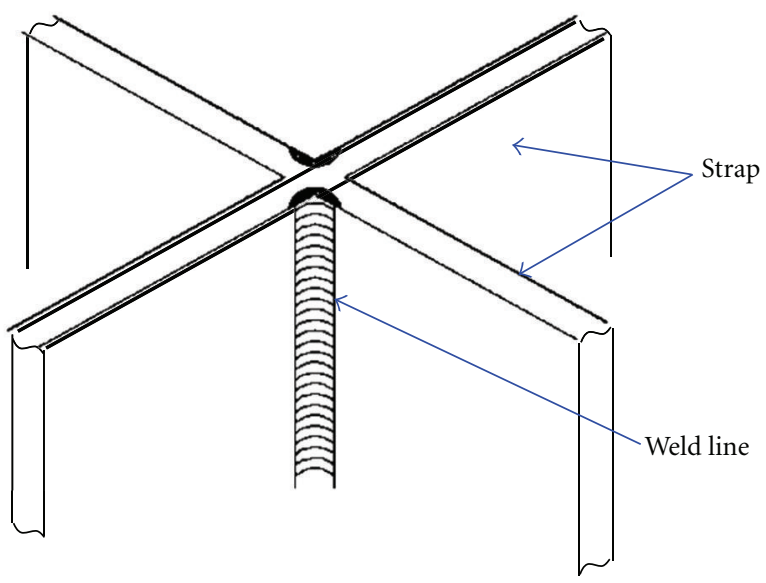

FIGURE 8: Line welding along the intersection of straps.

TABLE 1: Test condition of instrumented indentation.

\begin{tabular}{lc}
\hline Control type & Displace-controlled test \\
\hline Maximum indentation depth & $6 \mu \mathrm{m}$ \\
Number of indentation & 6 \\
Unloading rate & $50 \%$ \\
Test speed & $0.03 \mathrm{~mm} / \mathrm{min}$ \\
Equipment & Micro AIS \\
Indenter type & Sphere type indenter \\
Diameter of indenter & $0.05 \mathrm{~mm}$ \\
\hline
\end{tabular}

region through other methods such as uni-axial tension or a compression test. An instrumented indentation method continuously measures the load and depth if an indentation is made. The derived indentation load-depth curve, shown in Figure 3, can thus be used to determine the mechanical properties. In this study, a continuous indentation tester was used to measure the indentation load-depth curve for Zircaloy-4 and Hastelloy-X welded specimens using a
TABle 2: Chemical composition (wt\%) of Zircaloy-4.

\begin{tabular}{lcccc}
\hline $\mathrm{Zn}$ & $\mathrm{Sn}$ & $\mathrm{Fe}$ & $\mathrm{Cr}$ & $\mathrm{Fe}+\mathrm{Cr}$ \\
\hline Rest & $1.20-1.70$ & $0.18-0.24$ & $0.07-0.13$ & $0.28-0.37$ \\
\hline
\end{tabular}

spherical ball. The test condition using the indentation tester is summarized in Table 1. Based on the load-depth curve, mechanical properties such as yield stress and tensile strength are obtained using the algorithm in the continuous indentation tester [12].

3.2. Welded Zircaloy-4 Strip. Zircaloy-4 of zirconium alloy is used as the structural material of nuclear fuel since it has a superior combination of neutron economy (low absorption cross-section), high strength to resist deformation, high corrosion resistance to coolant, fuel, and fission products, and high reliability. The chemical composition of Zircaloy- 4 is summarized in Table 2 [13]. Figure 4 shows an etched specimen and its indented positions for taking 


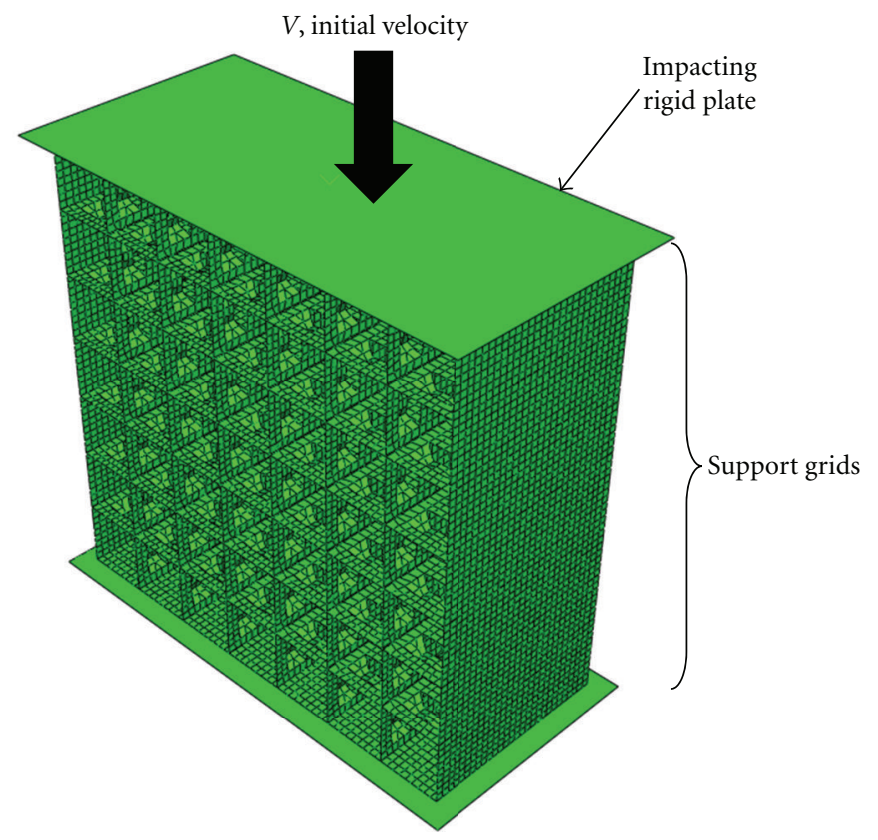

FigURE 9: FE model of subsize $(7 \times 7$ array $)$ spacer grid.

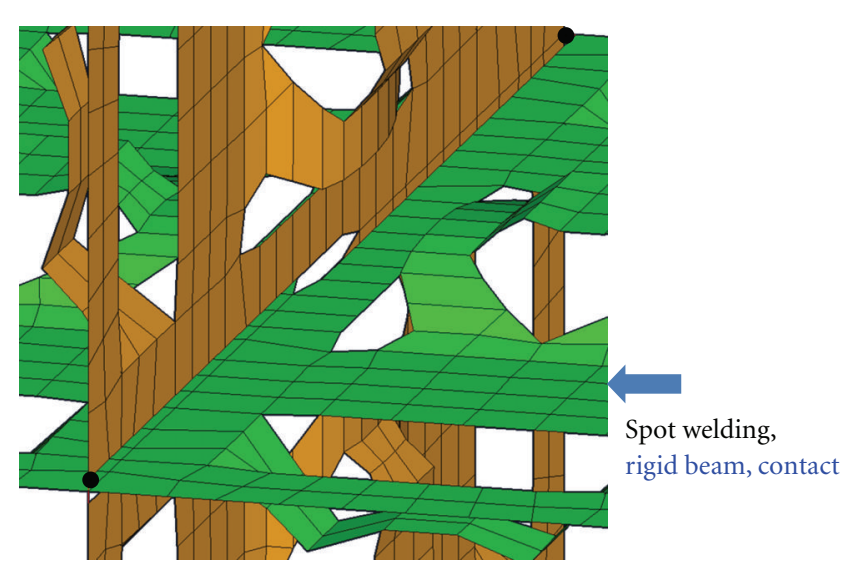

(a) P-spot welding

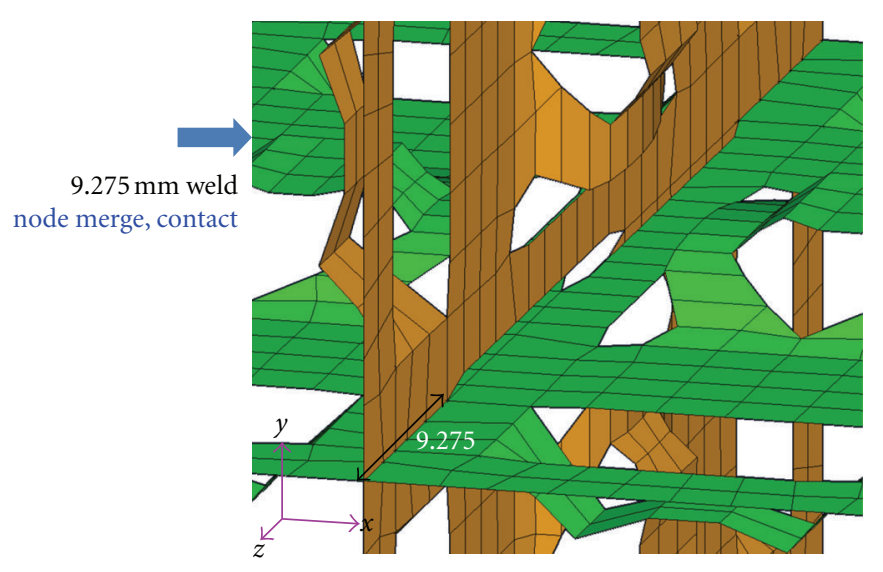

(b) P-9.275 mm

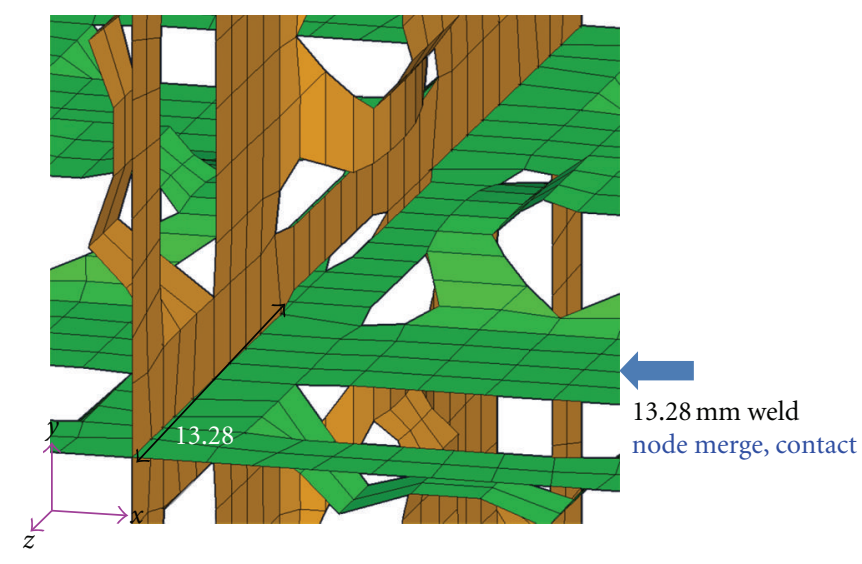

(c) P-13.28 mm

FIGURE 10: FE models using base material properties. 


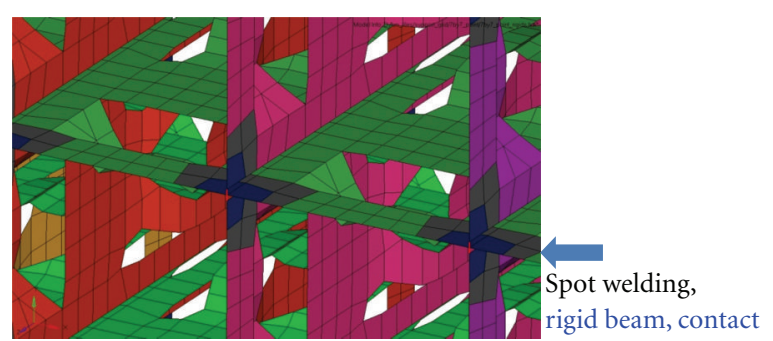

(a) W-spot welding

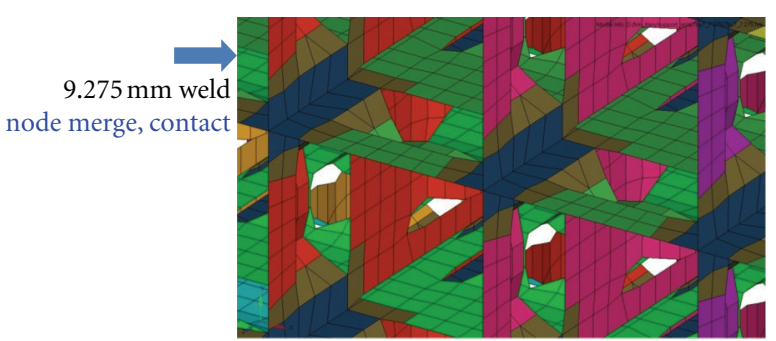

(b) W-9.275 mm

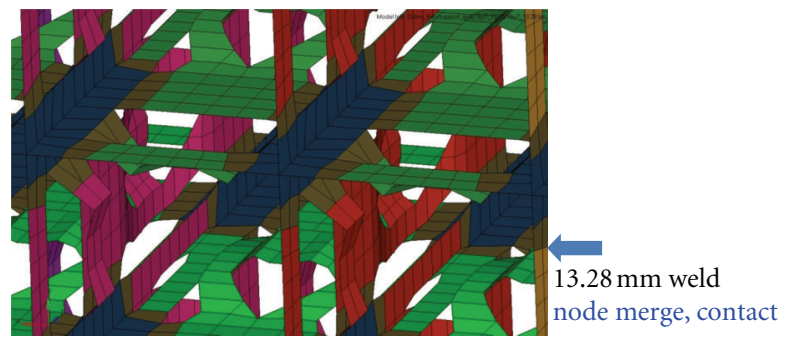

Fusion zone

HAZ

(c) $\mathrm{W}-13.28 \mathrm{~mm}$

FIgURE 11: FE models using weld material properties.

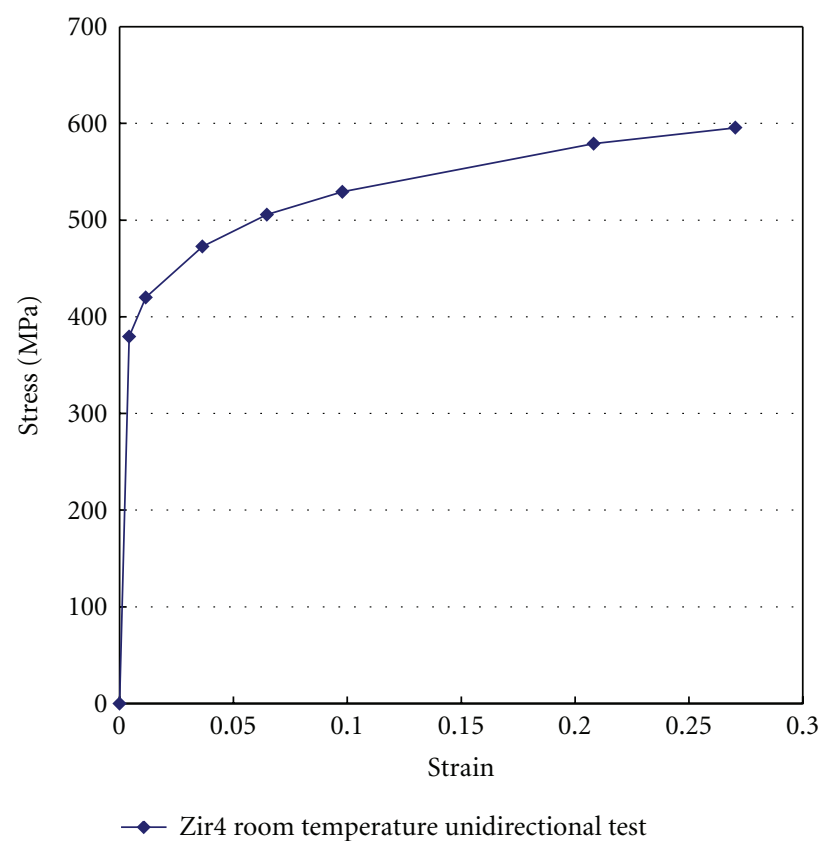

Figure 12: Stress-strain curve of Zircaloy-4.

the mechanical properties of the base material, the weld bead (or fusion zone), and the HAZ of the specimen. Figure 5 shows variations of the mechanical properties along lines L1 through L4, as shown in Figure 4. According to Figure 5, variations of tensile strength and yield stress are dominant in the weld zone including the weld bead and the HAZ as compared with the base material.
3.3. Analysis of Measured Data. The average values of the mechanical properties in the base material, weld bead, and HAZ are obtained using the measured data shown in Figure 5. Based on the average mechanical properties in the base material, the normalizing factors are obtained [11] in the weld and HAZ to be utilized in the strength analysis later. The normalizing factors in the base material, the weld, and 


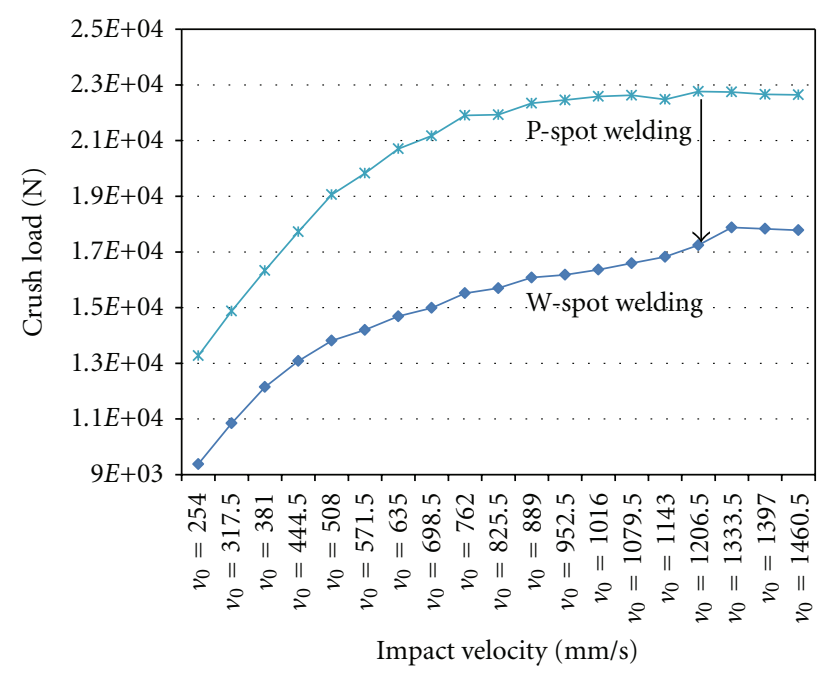

W Weld properties

P Parent material properties

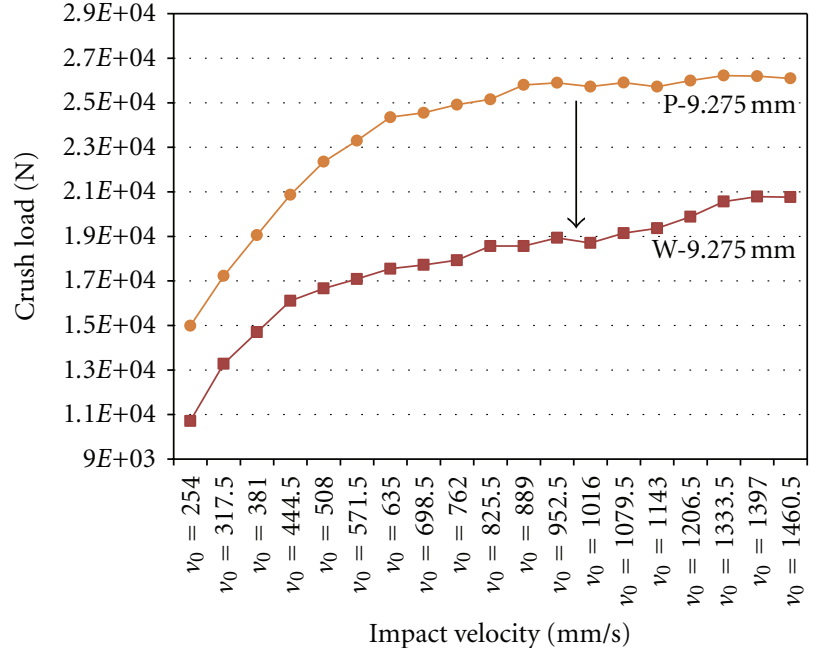

W Weld properties

P Parent material properties

(b) W-9.275 mm

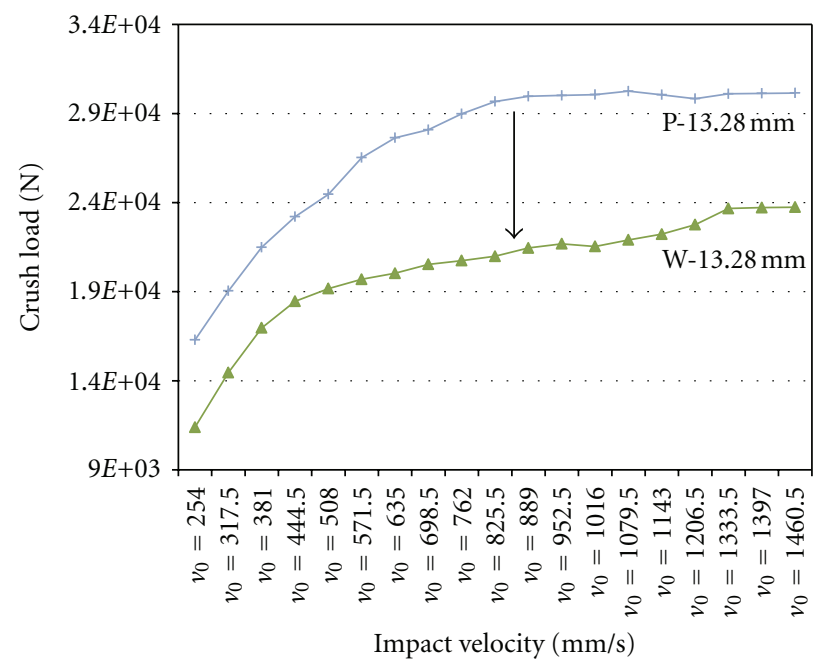

W Weld properties

$\mathrm{P}$ Parent material properties

(c) $\mathrm{W}-13.28 \mathrm{~mm}$

FIgURE 13: Crush load versus impact velocity.

HAZ are summarized in Table 3. According to Table 3, the mechanical properties in the weld bead (or fusion zone), HAZ, and base material are different to some extent and, thus, might affect the structural behavior and crush strength of the spacer grid.

\section{Strength Analysis and Discussion}

4.1. Finite Element Modeling. When performing a crush strength test and analysis on a full-size spacer grid $(16 \times 16$ array) as shown in Figure 6, it requires too much time and cost to fabricate and model the full-size spacer grid specimen. Previous research $[4,6]$ reported that a subsize spacer grid specimen $(7 \times 7$ array) shows the crush strength tendency of the full-size spacer grid well when estimating the crush strength. Thus, as an alternative, a crush strength test and analysis on the subsize spacer grid specimen shown in Figure 7 is going to be carried out in this study. Geometric data of the subsize spacer grid are summarized in Table 4. To obtain more data for a comparison with the test and analysis results, three kinds of subsize spacer grid specimen with different weld penetration, namely, one by spot welding and two by line welding, as shown in Figure 8, have been prepared. A crush strength test was performed on 5 specimens and the average crush strength was obtained.

An FE model for predicting the crush strength of the subsize spacer grid has been established, reflecting a real test environment. Figure 9 shows the FE model of the subsized 


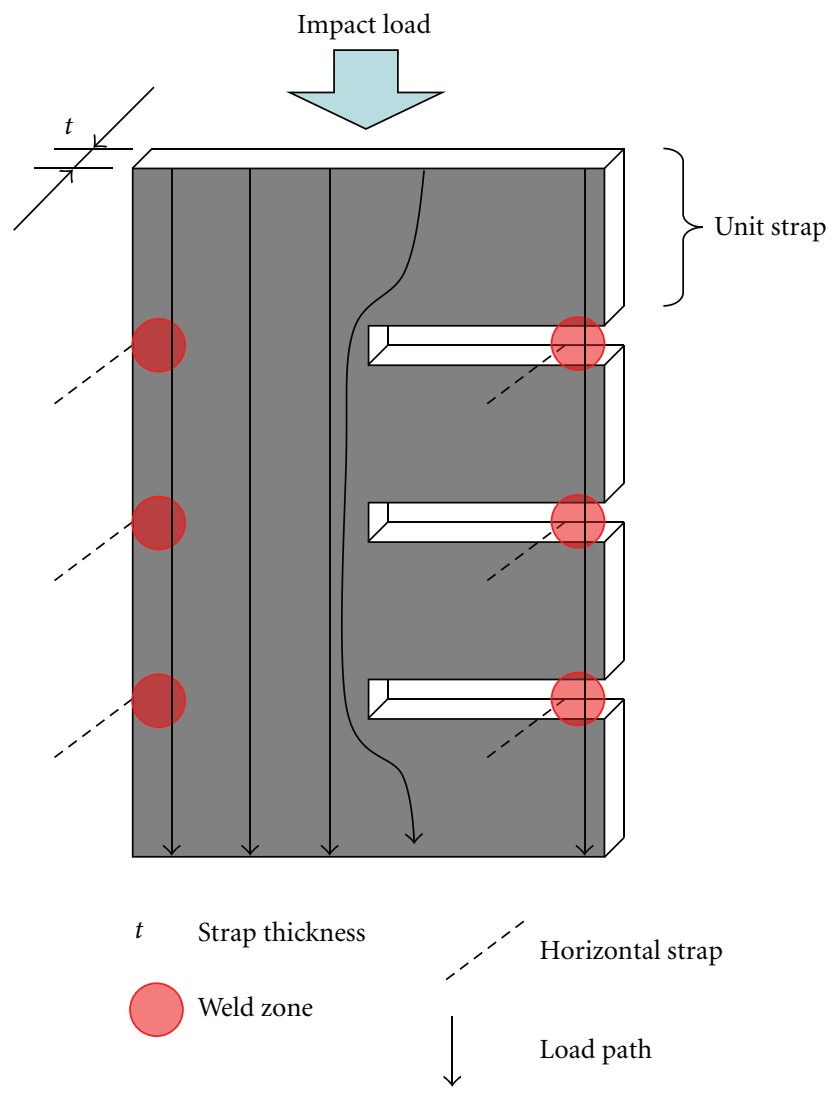

Figure 14: Load path in a strap.

TABLE 3: Normalized mechanical properties of Zircaloy-4 weld strip.

\begin{tabular}{lcc}
\hline & Yield stress & Tensile strength \\
\hline Base material & 1.000 & 1.000 \\
HAZ & 1.167 & 1.163 \\
Weld & 1.373 & 1.492 \\
\hline
\end{tabular}

spacer grid and the boundary condition. As shown in Figure 9, a rigid and mass element was used for simulating the impact hammer and all degrees of freedom were fixed at the rigid surface of the bottom side. The applied boundary condition simulated the actual test condition. The initial impact velocity at the reference node (at the center of the upper rigid surface) is applied, and the output accelerations for the initial impact velocity are obtained at this node.

The 4-node shell elements were used for the inner/outer straps. Since the slot width in the inner straps is wider than the inner strap thickness, there may be a gap at the interconnected parts. Thus, surface-to-node contact elements were used at these interconnected parts to simulate the gap conditions. The FE model is composed of 24,448 2D linear quadrilateral shell elements. Three kinds of FE model with different weld penetration are formulated for the base material properties shown in Figure 10 and for the weld material properties shown in Figure 11.
TABLE 4: Geometric data for the subsize $(7 \times 7$ array $)$ spacer grid specimen.

\begin{tabular}{cccc}
\hline \multirow{2}{*}{ Specimen $(7 \times 7$ type $)$} & \multicolumn{3}{c}{ Strap thickness $(\mathrm{mm})$} \\
& Outer strap A & Outer strap B & Inner strap \\
\hline 0.664 & 0.457 & 0.457 \\
\hline
\end{tabular}

4.2. Finite Element Analysis and Discussion. Crush strength analyses are carried out using a commercial FE code LSDYNA [14]. Figure 12 shows the elastic-plastic stress-strain curve of Zircaloy-4 from the unidirectional tensile test [15]. For the crush strength analysis using the base material properties, the stress-strain curve shown in Figure 12 is used as the material properties. On the other hand, for the crush strength analysis using the weld material properties, stressstrain curves in the weld zone including weld and HAZ are generated by multiplying the stress-strain curve of Figure 12 by normalizing the factors in Table 3 . The reaction force of the subsize spacer grid at each impact velocity is evaluated by multiplying the maximum acceleration of the model by the mass of the impact hammer. The reaction force, in other words, the crush load, increases as the impact velocity increases.

Figure 13 shows the results of crush strength analyses on the three kinds of FE model for using the base material 


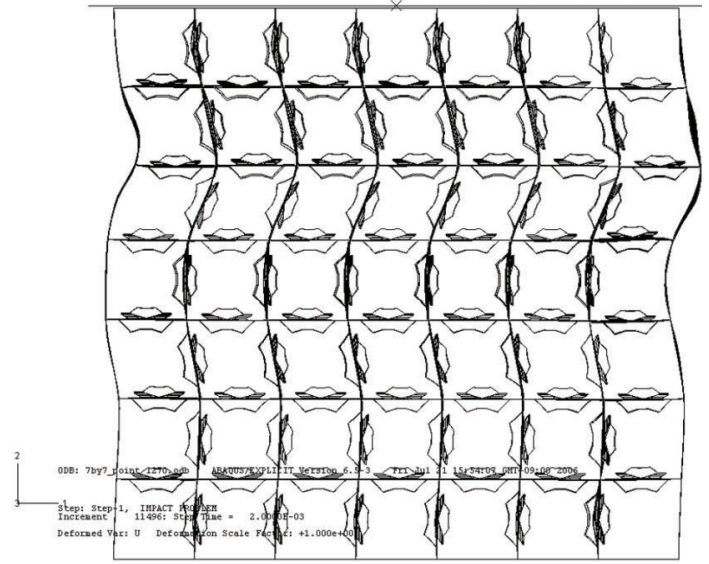

(a) P-spot welding

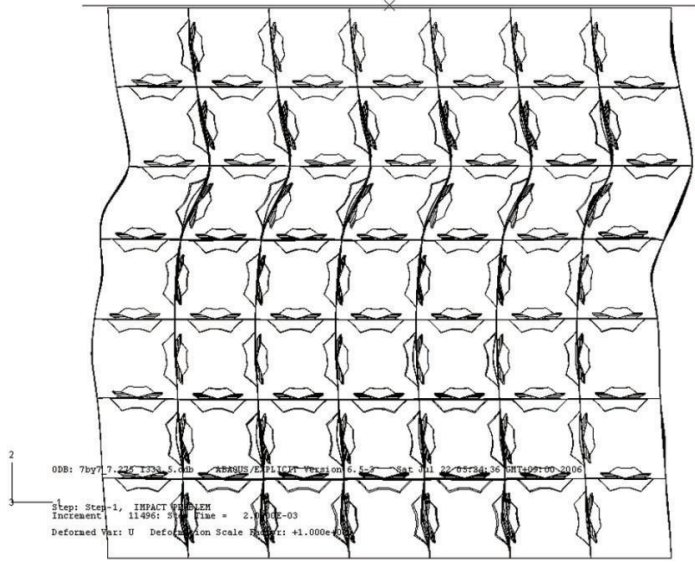

(b) $\mathrm{P}-9.275 \mathrm{~mm}$

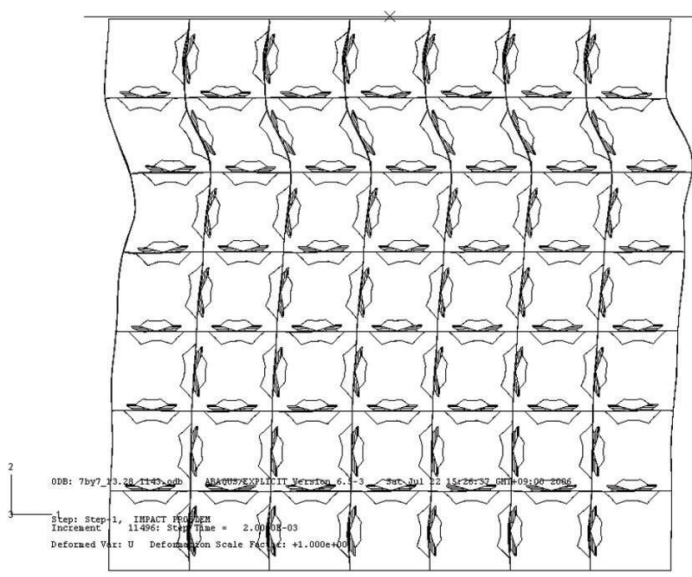

(c) P-13.28 mm

FIGURE 15: Deformed shape using base material properties at maximum crush load.

properties and weld properties. According to Figure 13, the crush load increases and becomes saturated to the maximum values as the impact velocity increases, and the maximum crush loads using weld material properties for three FE models are about $30 \%$ lower than those using base material properties. In addition, the crush load increases as the weld line increases from spot welding $(2.0 \mathrm{~mm})$ to line welding of $13.28 \mathrm{~mm}$ due to the increase of effective height of the strap discussed by Song et al. [4-6]. The crush strength is taken as the crush load from this case, where the linear slope of the crush load-impact velocity curve as shown in Figure 13 is apparently changed (over 5\%) [4]. Comparisons of crush strength ratios are summarized in Table 5. According to Table 5, the crush strength ratio, in other words, the crush strength, obtained from an FE analysis on the Zircaloy spacer grid using the base properties is overestimated by up to about $90 \%$, while the crush strength from using the weld mechanical properties is overestimated by up to about $50 \%$. In addition, the crush strength of the Zircaloy spacer grid obtained from the FE analyses using the weld material properties closes the gap in the test results compared to those from the analyses using the base material properties. The reason for this seems to be attributed to yielding and
TABLE 5: Comparisons of crush strength ratio.

\begin{tabular}{|c|c|c|}
\hline \multirow[b]{2}{*}{ Weld line (mm) } & \multicolumn{2}{|c|}{ Analysis/Test } \\
\hline & $\begin{array}{c}\text { with base material } \\
\text { properties }\end{array}$ & $\begin{array}{c}\text { with weld material } \\
\text { properties }\end{array}$ \\
\hline Spot welding $(2.0 \mathrm{~mm})$ & 1.94 & 1.43 \\
\hline Line welding $(9.275 \mathrm{~mm})$ & 1.93 & 1.49 \\
\hline Line welding $(13.28 \mathrm{~mm})$ & 1.90 & 1.51 \\
\hline
\end{tabular}

deforming first in the base material of the strap with a lower yield stress, while yielding in the weld zone with a higher yield stress seems to be delayed as shown in Figure 14 . Consequently, for a more reliable crush strength analysis on the Zircaloy spacer grid, FE analysis considering the weld material properties is necessary instead of an FE analysis using the base material properties.

Figures 15 and 16 show deformed shapes of the three kinds of FE model using the base material properties and weld properties at the maximum crush load, respectively, for the sake of understanding the deformation behavior of the subsize FE models. 


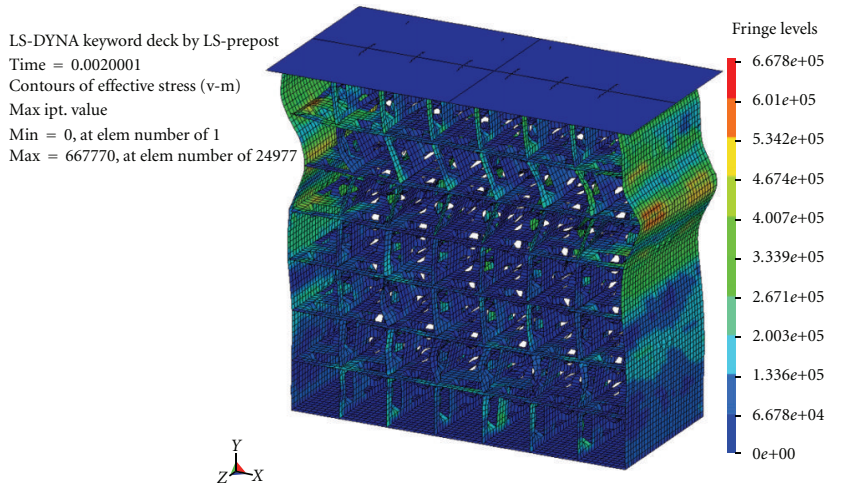

(a) P-spot welding

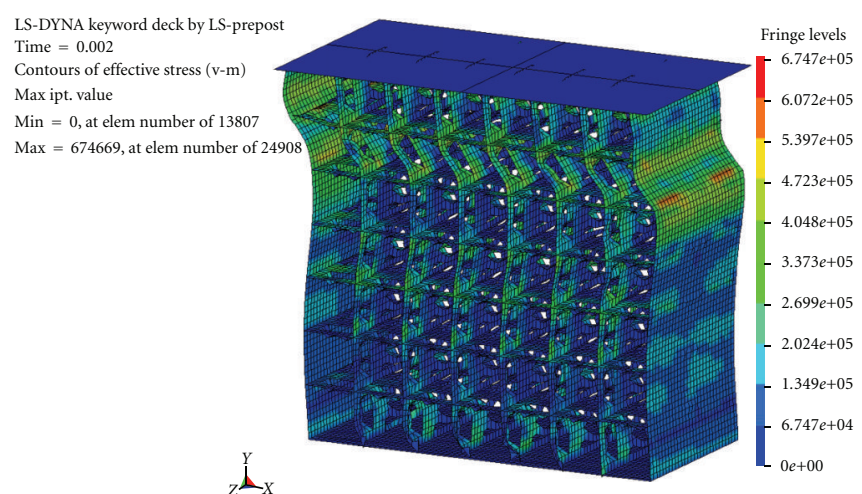

(b) $\mathrm{P}-9.275 \mathrm{~mm}$

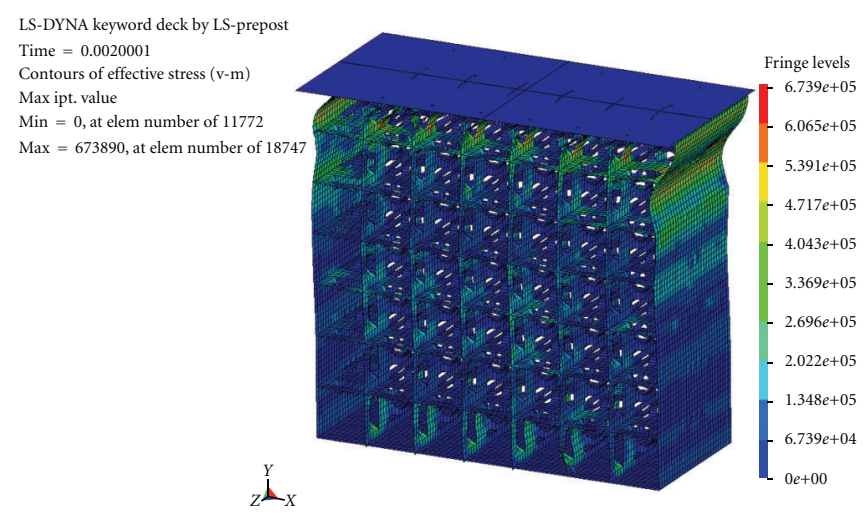

(c) $\mathrm{P}-13.28 \mathrm{~mm}$

FIGURE 16: Deformed shape using weld material properties at maximum crush load.

\section{Conclusions}

In this study, to investigate the effects of the mechanical behavior of the spacer grid when using weld mechanical properties, strength analyses considering the weld mechanical properties obtained by an instrumented indentation technique were performed, and the analysis results were compared with the previous research using the base material properties. As a result of the analysis, the following conclusions are drawn.

(1) The crush load when using the weld material properties is about $30 \%$ lower than that when using the base material properties for a crush strength analysis of the Zircaloy spacer grid.

(2) The crush strength of the Zircaloy spacer grid obtained from the analyses using the weld material properties closes a gap in the test results compared to those from the analyses using the base material properties.

(3) Thus, for a more reliable strength analysis on the Zircaloy spacer grid, an FE analysis considering the weld material properties is necessary.

\section{References}

[1] H. J. Kunz and K. N. Song, Fuel assembly mechanical design, Siemens/KWU Work-report U6/312/87/e326, Siemens/KWU, 1987.

[2] K. N. Song and S. S. Kim, "Determination of optimum LASER welding parameters and the development of a LASER welding technique to enhance the lateral impact strength of a spacer grid assembly for a PWR fuel assembly," Materials Science Forum, vol. 580-582, pp. 147-150, 2008.

[3] E. George Linnert, Welding Metallurgy 1, American Welding Society, New York, NY, USA, 1965.

[4] K. N. Song, S. B. Lee, M. K. Shin, J. J. Lee, and G. J. Park, "New spacer grid to enhance mechanical/structural performance," Journal of Nuclear Science and Technology, vol. 47, no. 3, pp. 295-303, 2010.

[5] S. B. Lee, Y. Kim, and K. Song, "Parameter study for a dimple location in a space grid under the critical impact load," Journal of Mechanical Science and Technology, vol. 22, no. 11, pp. 20242029, 2008.

[6] K. N. Song, "Laser welding unit for intersection line welding of spacer grid inner straps and its application," JLMN-Journal of Laser Micro/Nanoengineering, vol. 4, pp. 11-17, 2009.

[7] K. N. Song, S. H. Lee, and S. B. Lee, "Impact analysis and test for the spacer grid assembly of a nuclear fuel assembly," International Journal of Modern Physics B, vol. 22, no. 9-11, pp. 1228-1234, 2008.

[8] J. H. Ahn and D. Kwon, "Derivation of plastic stress-strain relationship from ball indentations: examination of strain 
definition and pileup effect," Journal of Materials Research, vol. 16, no. 11, pp. 3170-3178, 2001.

[9] ISO TR29381: Metallic materials-instrumented indentation test for measurement of indentation tensile properties, 2008.

[10] J. S. Lee, J. I. Jang, B. W. Lee, Y. Choi, S. G. Lee, and D. Kwon, "An instrumented indentation technique for estimating fracture toughness of ductile materials: a critical indentation energy model based on continuum damage mechanics," Acta Materialia, vol. 54, no. 4, pp. 1101-1109, 2006.

[11] K. N. Song and D. S. Ro, "Measurement of Mechanical Properties in Weld Zone of Nuclear Material Using an Instrumented Indentation Technique," Journal of the Korean Weldin and Joining Society, vol. 30, no. 3, pp. 249-254, 2012.

[12] D. I. Kown et al., "Introduction to instrumented indentation technique for evaluating tensile properties of ISO TR29381, representative stress-representative strain method," Trends in Metals and Materials Engineering, vol. 22, pp. 36-43, 2009.

[13] Technical data sheet: reactor grade zirconium alloys for nuclear waste disposal, http://www.wahchang.com/.

[14] “LSTC LS-DYNA Keyword User's Manual,” 2006, ver. 971.

[15] Standard test for tension testing of metallic materials [metric], ASTM E8M-04, 2004. 

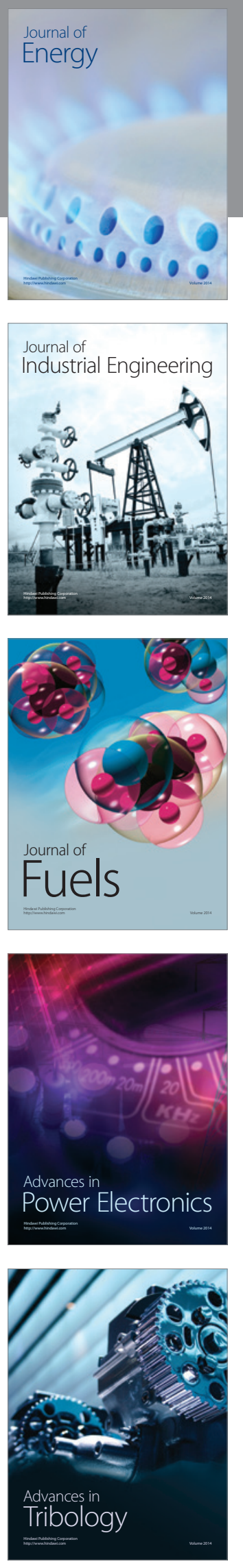
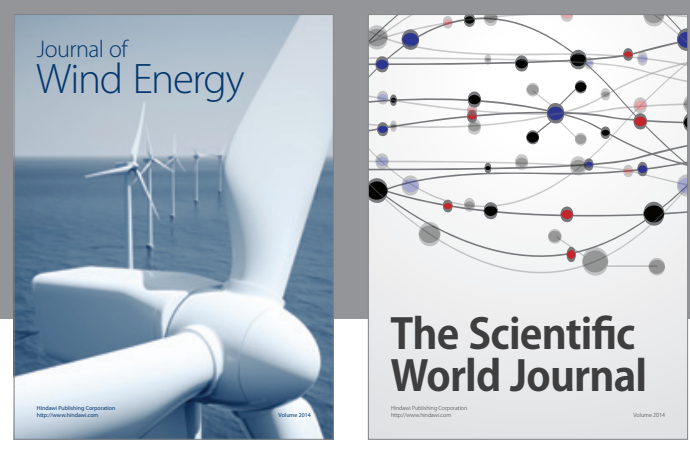

The Scientific World Journal

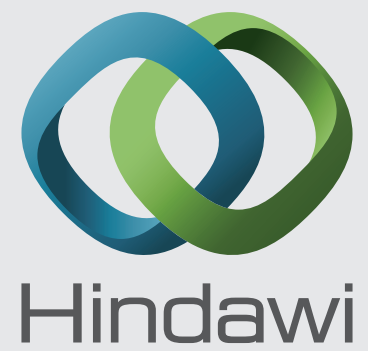

Submit your manuscripts at http://www.hindawi.com
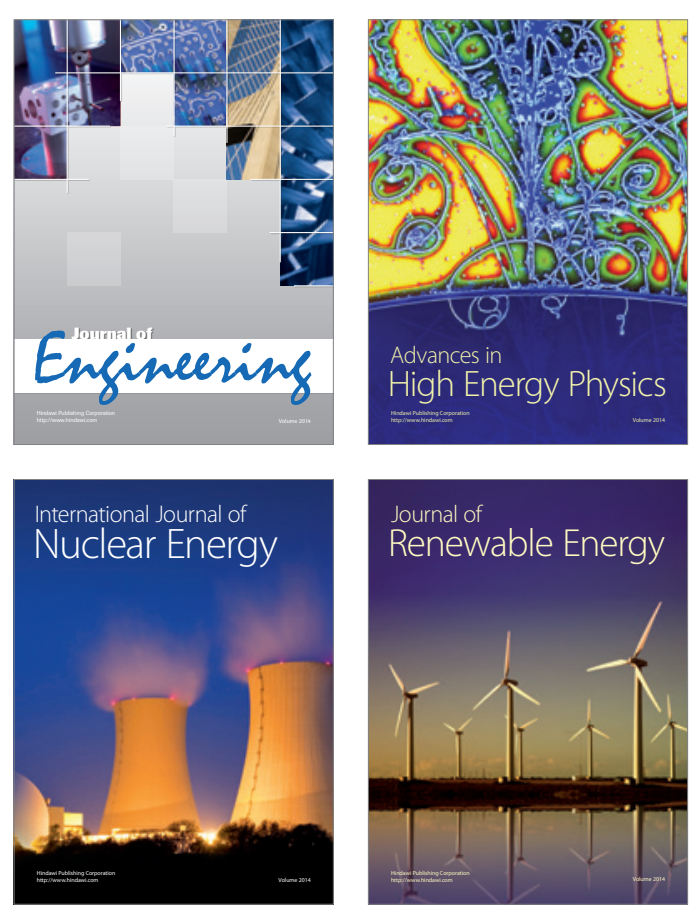

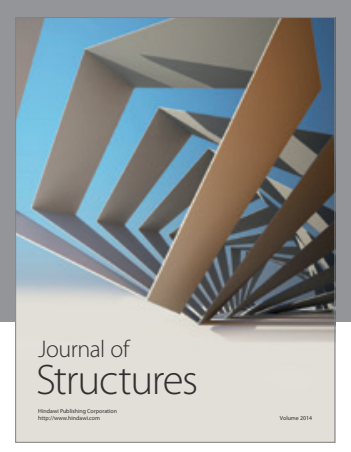

Rotating
Mechinery
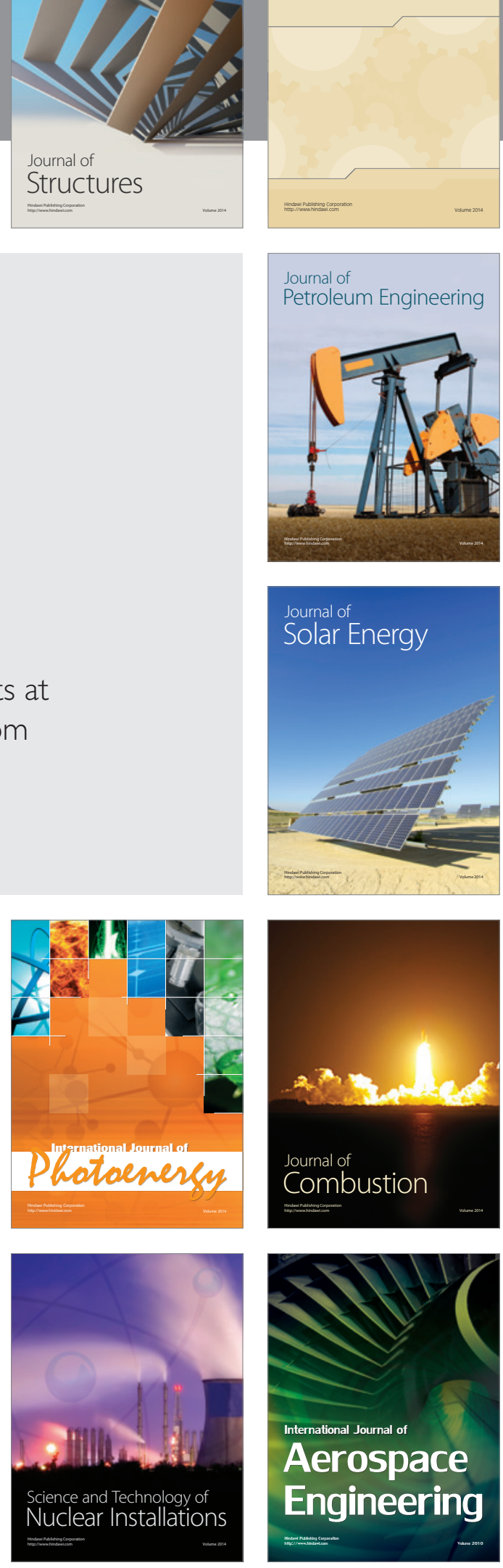